\title{
FEELING WITH THE SOUL
}

\section{Andrés Camilo Acosta Sánchez ${ }^{1}$ Erika Giseth Cristancho Sáenz ${ }^{2}$}

It is night, a cold night, sometimes it is warm, sometimes it is lonely. Sitting in front of my creative temple, I take a pause to breathe deeply. I close my eyes, inhale, exhale, one, two, three, four, up to five, although I am not sure of the exact time. I guess we are entering 10 p.m., the traffic noise is becoming lower. The talk and walk of people is increasingly tenuous; I know it's September $6^{\text {th }}$. Yesterday was Olivia's birthday. Oh! Beautiful Olivia, her sweet voice, her smell, her intelligence, that way she expresses herself. Deep sigh. Just thinking about it makes my creativity fly, muse of inspiration, platonic love ...

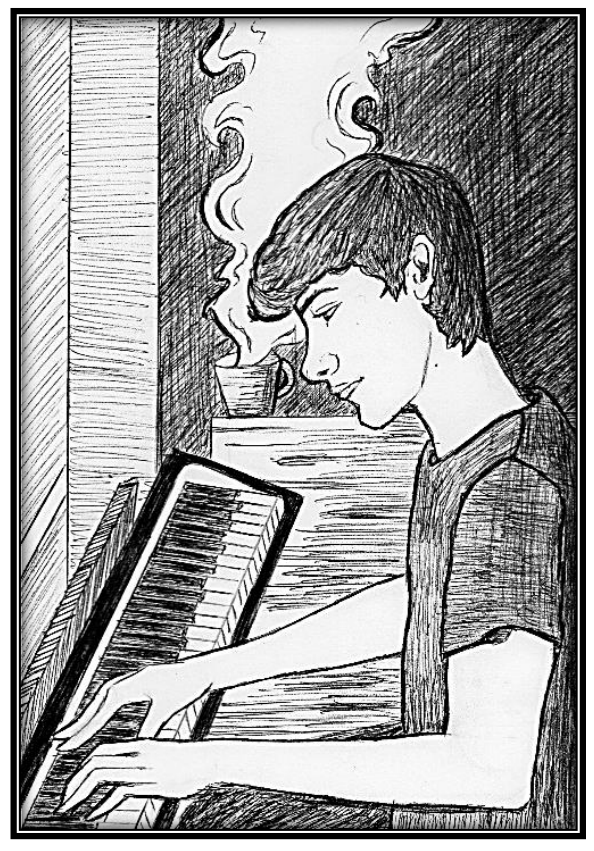

In my right hand, a hot coffee with a strong flavor and sweet aroma that invades my senses. My nose predicts what my taste buds confirm, an intense body of coffee. Perfection in a cup! It causes a number of sensations with each sip. Now, I more than ready to give free rein to my creativity. My fingers slowly move the piano keys I have in front of me, discovering those tonalities that could define you. "Olivia." A bass with a strong character and something melodic, maybe a little delicate at certain moments, sincere and cheerful piano accords, sometimes sad, but generally very happy...

\footnotetext{
1 Andrés Camilo Acosta Sánchez is an undergraduate music major at the Universidad Pedagógica y Tecnológica de Colombia. He is a live performer, finger drummer, DJ, composer, and producer. Andrés also plays multiple instruments.

${ }^{2}$ Erika Giseth Cristancho Sáenz is a Modern Languages student at the Universidad Pedagógica y Tecnológica de Colombia. She currently teaches Spanish at Colegio Comfaboy in Tunja, Boyacá, Colombia.
} 
With my left hand I take my electric guitar, maybe a simple riff, but moved and accompanied by a dancing, enveloping and solid percussion. Second pause, I take a deep breath. I exhale, one, two, three, four, five. The silence outside is almost absolute. I guess it's 3 a.m. Suddenly, the garage door opens in front of my house. He is the neighbor who confirms my suspicions with his departure. He usually leaves for work at that time. You hear a shout that says "Hurry Felipe, we have to leave ... do not delay." Felipe is his son.

Second cup of coffee. While I listen to what is going on in the composition, it is inevitable to imagine. Physically, it is impossible for me, and I do not dare, maybe it is what matters least to me. In my composition I lack more charisma, some more melody and movement lead me to include a wind instrument, my incomparable companion, the trumpet. With her I paint your smile once more, some more of piano and bass to finally overflow an improvisation with my whole being, with all my love and feeling with the soul. Olivia! The morning song of the birds tells me that it is almost 6 a.m. I breathe deeply. I exhale, one, two, three, four, five. I think I'm finished; it's time to get ready to leave.

It is 7 a.m., and I'm standing in a corner in front of my house. September $7^{\text {th }}$. Suddenly, a familiar smell comes to my nose. I tremble, I sweat, my heart accelerates more and more, suddenly a chill, "S@!\#”. It's undoubtedly her, she’s right in front of me. My throat is parched. I feel I can't speak. I stutter; she’s moving away. I am deconcentrated. Finally and fearfully I say, “Olivia”, once again, "Olivia”. Suddenly that voice, that tone, that personality, responds, “Who calls me?” Timidly, I say, “Olivia, it's me.” Step saliva, I say again, “Olivia, it's me," but this time with a lot of security, "I'm calling you, my name is Andrew, and I've composed this for you. I recorded it this morning on this CD, take it. Happy birthday!” Olivia responds, "Hello Andrew. I'm here, turn around. It's a very nice detail on your part, but ... why are you wearing sunglasses? It's 7 a.m." Andrew awkwardly runs his hands over his face causing his glasses to fall at Olivia's feet, who bends down to pick them up. Once she's going to deliver them he says, "Oh! Sorry, I did not know you were blind. I am late for class, I promise to hear it, again thank you very much, a very nice detail from you." She leaves hurriedly; seven seconds have passed and her smell has slowly begun to fade ... five, four, three, two, one..... 